\title{
RNA Interference inhibits Hepatitis B Virus of different genotypes in Vitro and in Vivo
}

\author{
Ya-Li Zhang, Tong Cheng*, Yi-Jun Cai, Quan Yuan, Che Liu, Tao Zhang, De-Zhen Xia, Rui-Yin Li, Lian-Wei Yang, \\ Ying-Bin Wang, Anthony ET Yeo, James Wai-Kuo Shih, Jun Zhang, Ning-shao Xia
}

\begin{abstract}
Background: Hepatitis B virus (HBV) infection increases the risk of liver disease and hepatocellular carcinoma. Small interfering RNA (siRNA) can be a potential new tool for HBV therapy. Given the high heterogeneity of HBV strains and the sensitivity towards sequences changes of siRNA, finding a potent siRNA inhibitor against the conservative site on the HBV genome is essential to ensure a therapeutic application.

Results: Forty short hairpin RNA (shRNA) expression plasmids were constructed to target conserved regions among nine HBV genotypes. HBV 1.3-fold genome plasmids carrying various genotypes were co-transfected with shRNA plasmids into either Huh7 cells or mice. The levels of various viral markers were examined to assess the anti-HBV efficacy of siRNA. Four (B245, B376, B1581 and B1789) were found with the ability to potently inhibit HBV RNA, DNA, surface antigen ( $\mathrm{HBsAg}$ ), e antigen ( $\mathrm{HBeAg}$ ) and core antigen ( $\mathrm{HBCAg}$ ) expression in HBV genotypes $\mathrm{A}$, $B, C, D$ and I (a newly identified genotype) in Huh7 cells and in mice. No unusual cytotoxicity or off-target effects were noted.
\end{abstract}

Conclusions: Such siRNA suggests an alternate way of inhibiting various HBV genotypes in vitro and in vivo, promising advances in the treatment of HBV.

\section{Background}

Worldwide, there are over 350 million people persistently infected with hepatitis B virus (HBV) [1]. Chronic HBV infections may have serious consequences, including acute hepatitis, as well as chronic hepatitis, cirrhosis, and hepatocellular carcinoma (HCC) [2]. Together, these are responsible for over 1 million deaths worldwide each year [3]. Current treatments for HBV infections are not only expensive and have significant side effects, but also only induce a partial response [4-6].

In eukaryotic cells, RNA interference (RNAi), a type of double-stranded (ds) RNA, initiates and directs sequence-specific, post-transcriptional silencing of homologous genes $[7,8]$. It has been demonstrated in previous studies that expression and replication of $\mathrm{HBV}$ can be suppressed by siRNA or shRNA with clinical implications [9-11]. However, the wide heterogeneity of HBV sequences may render RNAi inhibitors ineffective.

\footnotetext{
* Correspondence: tcheng@xmu.edu.cn

National Institute of Diagnostics and Vaccine Development in Infectious Diseases, School of Life Science, Xiamen University, Xiamen, Fujian Province, China
}

(c) 2010 Zhang et al; licensee BioMed Central Ltd. This is an Open Access article distributed under the terms of the Creative Commons Attribution License (http://creativecommons.org/licenses/by/2.0), which permits unrestricted use, distribution, and reproduction in any medium, provided the original work is properly cited.
To explore this further, 40 shRNA expression plasmids were constructed to target the sites that were conserved among HBV genotypes A through I. Their anti-HBV efficacy was then evaluated in vitro and in vivo.

\section{Results}

\section{Screening for effective and broad anti-HBV shRNA}

The shRNA plasmids co-transfected with two HBV 1.35 plasmids (N10 and Y1021) exhibited varying levels of extracellular HBsAg expression (Table 1). Of the forty shRNA plasmids, four plasmids (B245, B376, B1581 and B1789, Figure 1) were selected as candidates for further research based on their remarkable inhibitory ability and also relatively lower off-target probability (off-target score of above 30). The sequence conservation among the A to I genotypes for B245, B376, B1581 and B1789 were $95.1 \% \quad(95 \% \mathrm{CI}: \quad 92.2 \sim 97.2), \quad 88.7 \% \quad(95 \% \mathrm{CI}$ : 84.7 91.9), 97.3\% (95\%CI: 94.8 98.7), and 97.6\% (95\% CI: 95.2 98.9), respectively (Table 2 ). The data also shows that the target sequences of B245, B1581 and B1789 were more conserved than the target sequence of B376 $(\mathrm{p}<0.05)$ in genotype B and C (Table 2). 
Table 1 The characterization and screening for multiplex anti-HBV siRNA

\begin{tabular}{|c|c|c|c|c|c|c|c|}
\hline ID & Sequence & Start Position & Off-target number $^{a}$ & off-target score ${ }^{a}$ & Genome localization & Anti- Y1021 & Anti- N10 \\
\hline B182 & GGACCCCTGCTCGTGTTACAG & 182 & 8 & 30 & $S, P$ & ++ & + \\
\hline B183 & GACCCCTGCTCGTGTTACAGG & 183 & 3 & 30 & $S, P$ & - & - \\
\hline B184 & ACCCCTGCTCGTGTTACAGGC & 184 & 3 & 30 & $S, P$ & - & - \\
\hline B243 & AGAGTCTAGACTCGTGGTGGA & 243 & 3 & 30 & $S, P$ & + & + \\
\hline B244 & GAGTCTAGACTCGTGGTGGAC & 244 & 9 & 30 & $S, P$ & $\underline{+++}$ & $\underline{+++}$ \\
\hline B245 & AGTCTAGACTCGTGGTGGACT & 245 & 4 & 30 & $S, P$ & $\overline{+++}$ & $\overline{+++}$ \\
\hline B246 & GTCTAGACTCGTGGTGGACTT & 246 & 4 & 30 & $S, P$ & - & - \\
\hline B250 & AGACTCGTGGTGGACTTCTCT & 250 & 10 & 35 & $S, P$ & - & + \\
\hline B251 & GACTCGTGGTGGACTTCTCTC & 251 & 7 & 35 & $S, P$ & + & ++ \\
\hline B252 & ACTCGTGGTGGACTTCTCTCA & 252 & 2 & 30 & $S, P$ & ++ & ++ \\
\hline B375 & GGATGTGTCTGCGGCGTTTTA & 375 & 1 & 25 & $S, P$ & ++ & ++ \\
\hline B376 & GATGTGTCTGCGGCGTITTAT & 376 & 7 & 30 & $S, P$ & $\underline{+++}$ & $\underline{+++}$ \\
\hline B377 & ATGTGTCTGCGGCGTITATC & 377 & 5 & 35 & $S, P$ & + & ++ \\
\hline B379 & GTGTCTGCGGCGTITTATCAT & 379 & 4 & 35 & $S, P$ & + & + \\
\hline B410 & ATCCTGCTGCTATGCCTCATC & 410 & 76 & 25 & $S, P$ & - & - \\
\hline B415 & GCTGCTATGCCTCATCTTCTT & 415 & 54 & 25 & $S, P$ & + & ++ \\
\hline B456 & AAGGTATGTTGCCCGTTTGTC & 456 & 2 & 30 & $S, P$ & ++ & ++ \\
\hline B457 & AGGTATGTTGCCCGTTTGTCC & 457 & 1 & 40 & $S, P$ & - & + \\
\hline B458 & GGTATGTTGCCCGTTTGTCCT & 458 & 7 & 35 & $S, P$ & ++ & ++ \\
\hline B459 & GTATGTTGCCCGTITGTCCTC & 459 & 15 & 25 & $S, P$ & ++ & ++ \\
\hline B461 & ATGTTGCCCGTTTGTCCTCTA & 461 & 11 & 30 & $S, P$ & + & + \\
\hline B1260 & GCCGATCCATACTGCGGAACT & 1260 & 2 & 25 & Enhl, P & + & ++ \\
\hline B1577 & GTGTGCACTTCGCTTCACCTC & 1577 & 13 & 30 & $X, P, D R 1$ & +++ & ++ \\
\hline B1579 & GTGCACTTCGCTTCACCTCTG & 1579 & 5 & 25 & $X, P, D R 1$ & ++ & ++ \\
\hline B1581 & GCACTTCGCTTCACCTCTGCA & 1581 & 15 & 30 & $X, P, D R 1$ & $\underline{+++}$ & $\underline{+++}$ \\
\hline B1583 & ACTTCGCTTCACCTCTGCACG & 1583 & 21 & 30 & $X, P, D R 1$ & ++ & ++ \\
\hline B1787 & GGAGGCTGTAGGCATAAATTG & 1787 & 4 & 30 & Pc, Enhll & ++ & ++ \\
\hline B1788 & GAGGCTGTAGGCATAAATTGG & 1788 & 9 & 25 & PC, Enhll & ++ & + \\
\hline B1789 & AGGCTGTAGGCATAAATTGGT & 1789 & 5 & 30 & Pc, Enhll & $\underline{+++}$ & $\underline{+++}$ \\
\hline B1880 & AAGCCTCCAAGCTGTGCCTTG & 1880 & 3 & 30 & Pc & + & - \\
\hline B1881 & AGCCTCCAAGCTGTGCCTTGG & 1881 & 23 & 25 & Pc & - & - \\
\hline B2389 & AGAAGAAGAACTCCCTCGCCT & 2389 & 42 & 25 & $C, P$ & - & + \\
\hline B2390 & GAAGAAGAACTCCCTCGCCTC & 2390 & 26 & 25 & $C, P$ & - & + \\
\hline B2391 & AAGAAGAACTCCCTCGCCTCG & 2391 & 29 & 25 & $C, P$ & - & - \\
\hline B2392 & AGAAGAACTCCCTCGCCTCGC & 2392 & 19 & 30 & $C, P$ & - & + \\
\hline B2393 & GAAGAAGAACTCCCTCGCCTC & 2393 & 18 & 30 & $C, P$ & - & + \\
\hline B2394 & AAGAACTCCCTCGCCTCGCAG & 2394 & 29 & 25 & $C, P$ & - & + \\
\hline B2395 & AGAACTCCCTCGCCTCGCAGA & 2395 & 14 & 35 & $C, P$ & + & + \\
\hline B2396 & GAACTCCCTCGCCTCGCAGAC & 2396 & 18 & 35 & $C, P$ & - & + \\
\hline B2397 & GATCCATACTGCGGAACTCCT & 2397 & 11 & 35 & $C, P$ & - & - \\
\hline L1254 & TGGCTACATTCTGGAGACATA & NA & NA & NA & luciferase & - & - \\
\hline
\end{tabular}

NA, no application.

" + " indicates weak inhibition (below 50\%),

" ++ " indicates medium inhibition (above 50\%, but below 90\%),

"+++" indicates strong inhibition (above 90\%),

"_" indicates no significant inhibition,

An underline represents the four candidates that were worthy for further research.

a: off-target effects were evaluated by the online SOS program http://rnai.cs.unm.edu/offTarget.

b: anti-HBV effects were evaluated by decreases in extracellular HBsAg level. 


Figure 1 A schematic diagram depicting the locations of siRNA targets in association with viral open reading frames and viral mRNAs
within the HBV genome. The circular $\mathrm{HBV}$ genome is presented in a linear form. The coding regions for e/core, surface, polymerase, and $\mathrm{X}$
proteins are displayed and designated as $\mathrm{PC} / \mathrm{C}, \mathrm{S}, \mathrm{P}$, and $\mathrm{X}$, respectively. The relative locations of the target sites of B245, B376, B1581 and B1789
are also indicated by arrowheads.

\section{Adverse side-effects evaluation for selected shRNA plasmids}

The B245, B376, B1581, and B1789 plasmids were transfected into Huh7 cells to determine cytotoxicity by the WST-8 assay. No significant siRNA-induced cytotoxicity was observed for these siRNA when compared to an empty pSUPER vector ( $\mathrm{p}=0.66$, data not shown). The mRNA levels of four major interferon stimulated genes (STAT1, OAS1, GBP1 and MX1) in transfected cells were measured by quantitative realtime PCR with GAPDH mRNA acting as a control. As shown in Figure 2 , between values 1 and 2, logarithmic increases for the IFN-stimulatable mRNAs were only observed in the IFN-treated cells, but not observed in any of the shRNA treated cells vs. untreated cells. From this, it can be concluded that an IFN response is not activated by these anti-HBV siRNAs.

\section{ShRNA inhibit gene expression of HBV strains with different genotypes in vitro}

The levels of cytoplasmic HBV pg/pc RNA (3.5 kb) and HBV DNA in cultured supernatants were determined by realtime RT-PCR/PCR and presented in Figure 3. The $\mathrm{pg} / \mathrm{pc}$ RNA level of five HBV strains with different genotypes were reduced by 58\% 93\% in B245(69\% 93\%), B376(59\% 91\%), B1581(67\% 90\%) and B1789(58\% 88\%) treatments, while the HBV DNA level observed in supernatants was decreased by $77 \% \sim 99 \%$ in these shRNA plasmid treatments (B245: 83\% 99\%, B376: 79\% 99\%, B1581:88\% 98\%, B1789: 77\% 99\%).

In addition, the extracellular and intracellular antigen levels in Huh7 cells that were co-transfected with HBV and shRNA plasmids were also determined (Figure 4). In the shRNA-treated Huh7 cells, the average extracellular HBsAg expression level of all five HBV strains decreased by $1.66 \pm$

Table 2 Sequence conservation of four selected siRNA targets in 327 HBV strains

\begin{tabular}{|c|c|c|c|c|c|}
\hline \multirow[t]{2}{*}{$\begin{array}{c}\text { Genotype } \\
\text { (No. of HBV strains) }\end{array}$} & \multicolumn{4}{|c|}{$\begin{array}{c}\text { Number of strains with identical } \\
\text { sequence with siRNA(\%) }\end{array}$} & \multirow[t]{2}{*}{$\begin{array}{l}\text { Subtype } \\
\text { (No. of HBV strains) }\end{array}$} \\
\hline & B245 & B376 & B1581 & B2379 & \\
\hline Genotype A (63) & $61(96.8)$ & $62(98.4)$ & $62(98.4)$ & $63(100)$ & $\mathrm{Aa}(45), \mathrm{Ac}(9), \mathrm{Ae}(9)$ \\
\hline Genotype B(72) & 69(95.8) & $49(68.1)^{*}$ & $71(98.6)$ & $70(97.2)$ & $\mathrm{Bj}(9), \mathrm{Ba}(38), \mathrm{B} 3(7), \mathrm{B} 4(8), \mathrm{B} 5(4), \mathrm{B} 6(6)$ \\
\hline Genotype C(58) & 53(91.4) & $46(79.3)^{*}$ & $57(98.3)$ & $56(96.6)$ & C1(38), C2(13), C3(2), C4(2), C5(3) \\
\hline Genotype D(30) & 29(96.7) & 29(96.7) & 28(93.3) & 28(93.3) & D1(11), D2(6), D3(8), D4(5) \\
\hline Genotype E(34) & $33(97.1)$ & $34(100)$ & 33(97.1) & $33(97.1)$ & $F 1(4), F 2(14)$ \\
\hline Genotype F(18) & 15(83.3) & 18(100) & 18(100) & 18(100) & \\
\hline Genotype G(17) & $17(100)$ & $17(100)$ & 15(88.2) & 16(94.1) & \\
\hline Genotype H(13) & 13(100) & 13(100) & 12(92.3) & 13(100) & \\
\hline Genotype I(22) & $21(95.5)$ & $22(100)$ & $22(100)$ & $22(100)$ & $\mid 1(10), 12(12)$ \\
\hline Total (327) & $311(95.1)$ & $290(88.7)^{*}$ & 318(97.3) & 319(97.6) & \\
\hline
\end{tabular}

\footnotetext{
${ }^{a}$ : An asterisk represents a statistical difference of $P<0.05$ in comparison with $B 376$ and others.
} 


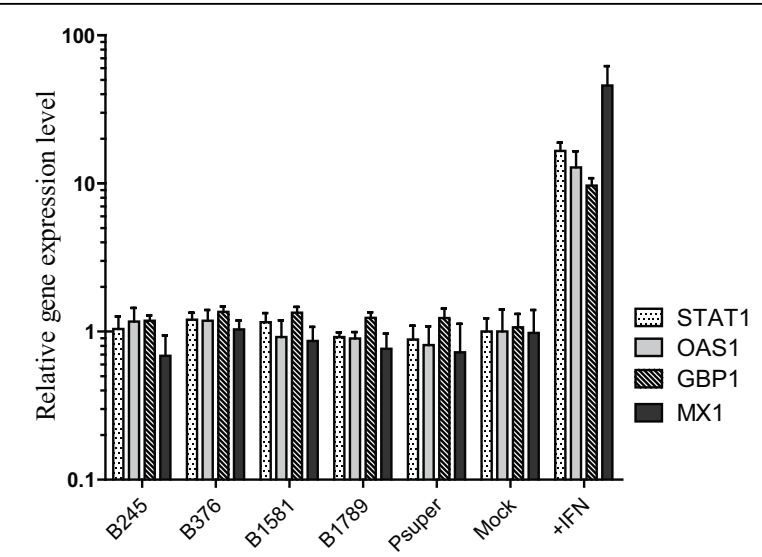

Figure 2 The expression profile of four major interferon stimulated genes (ISGs) in shRNA plasmids transfected cells.

Cytoplasmic RNAs, from Huh7 cells treated with or without IFNa-2a or transfected with either PSUPER vector or shRNA plasmids, were analysed by realtime RT-PCR for IFN stimulated genes STAT1, OAS1, GBP1 and MX1. The values on the figure, plotted as "Relative gene expression level" on the $y$-axis, were calculated as the mRNA levels of ISGs divided by the GAPDH (control) mRNA level. Student t test was used to assess the difference between shRNA plasmids (including empty PSUPER vector) of transfected cells and nontransfected cells (mock). No significant difference was observed.

0.36 logs. The average intracellular HBsAg expression level decreased by $1.47 \pm 0.33 \operatorname{logs}$, while the extracellular HBeAg levels decreased by $1.04 \pm 0.23$ logs, and the intracellular HBcAg levels by $1.71 \pm 0.49$ logs. The effect of the siRNA treatment on $\mathrm{HBeAg}$ levels was weaker than that on the HBsAg or HBcAg levels $(\mathrm{P}<0.001$, Figure 5$)$.

\section{Inhibition of gene expression of HBV strains with different genotypes in vivo}

Using the mouse model of acute hepatitis B virus infection [12], the profiles of serum HBsAg and HBeAg were used to evaluate the effect of shRNA over nine days (Figure 6). All HBV plasmids expressed detectable HBsAg and HBeAg in mice sera (Figure 6). As compared to the control mice (HBV+L1254), B245 and B376 treatments reduced HBsAg expression by over $99 \%$ in all five HBV genotypes. Furthermore, B1581 and B1789 treatments suppressed HBsAg by over $99 \%$ in mice infected with HBV genotypes A, B, C and D. In a novel W29 strain representing genotype I however, B1581 and B1789 treatments only reduced HBsAg expression by about $90 \%$. With regards to serum HBeAg for genotypes A, B, C, D and I, B245, B376, B1581 and B1789 treatments suppressed HBeAg by $96 \%$ 99\%, 79\% 99\%, 94\% 99\%, and 89\% 99\%, respectively. The overview of the results shows that B245 is the most potent agent.

\section{Discussion}

Activated RNAi pathway can silence HBV replication and expression $[13,14]$. However, in most previous studies, the activity of RNAi against HBV is often evaluated with only one HBV strain [15-18]. Nine HBV genotypes (including a newly identified genotype "I"), designated as the letters A through I, have been recognized with an accompanying sequence divergence of $>8 \%$ over the entire genome [19-21]. The influence of genotypes on HBV replication efficacy and antigen expression level had been proved to be various and that may further associate with clinical outcomes and antiviral treatments responses [22]. Hence, RNAi designed for one genotype may not necessarily be effective against another genotype. Given the high heterogeneity of HBV strains and the sensitivity of siRNA to the sequence changes, designing siRNA targets against the conservative site on HBV genome is essential to ensure activity across all genotypes [23].

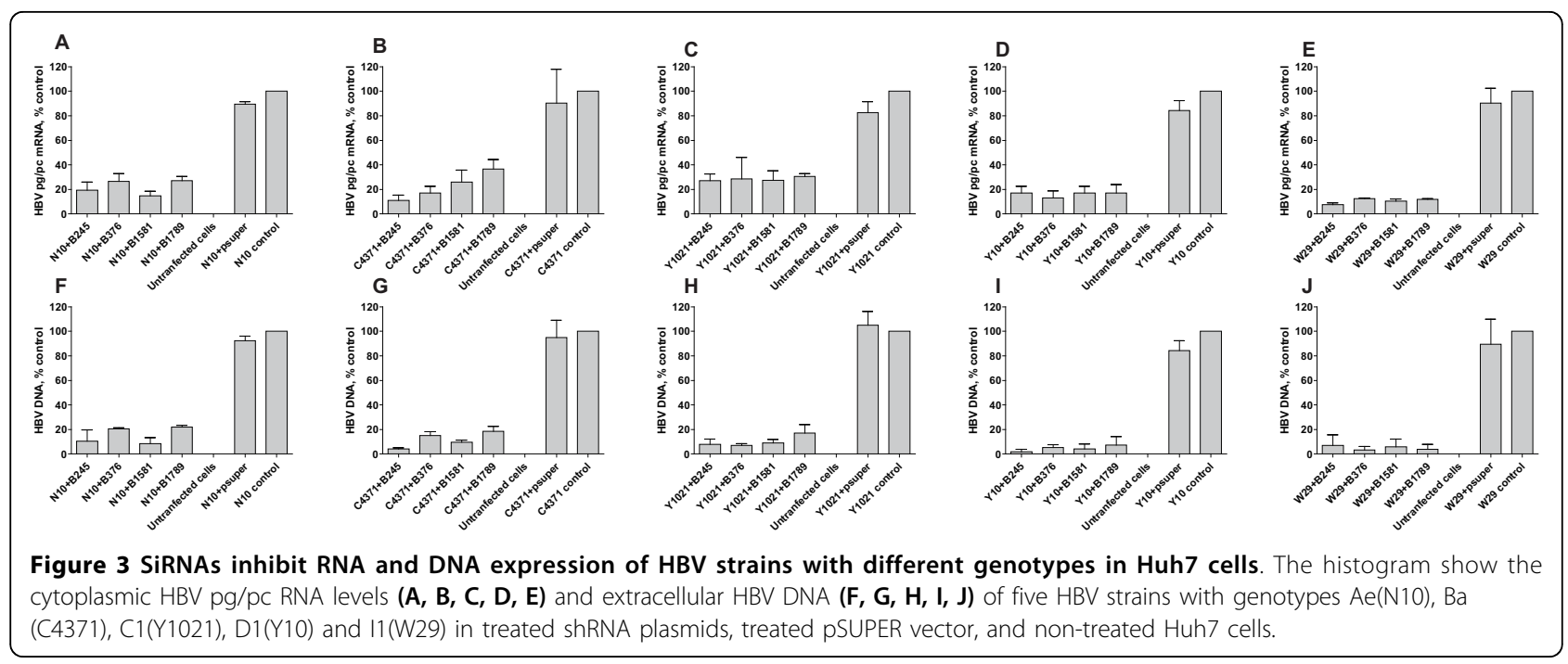




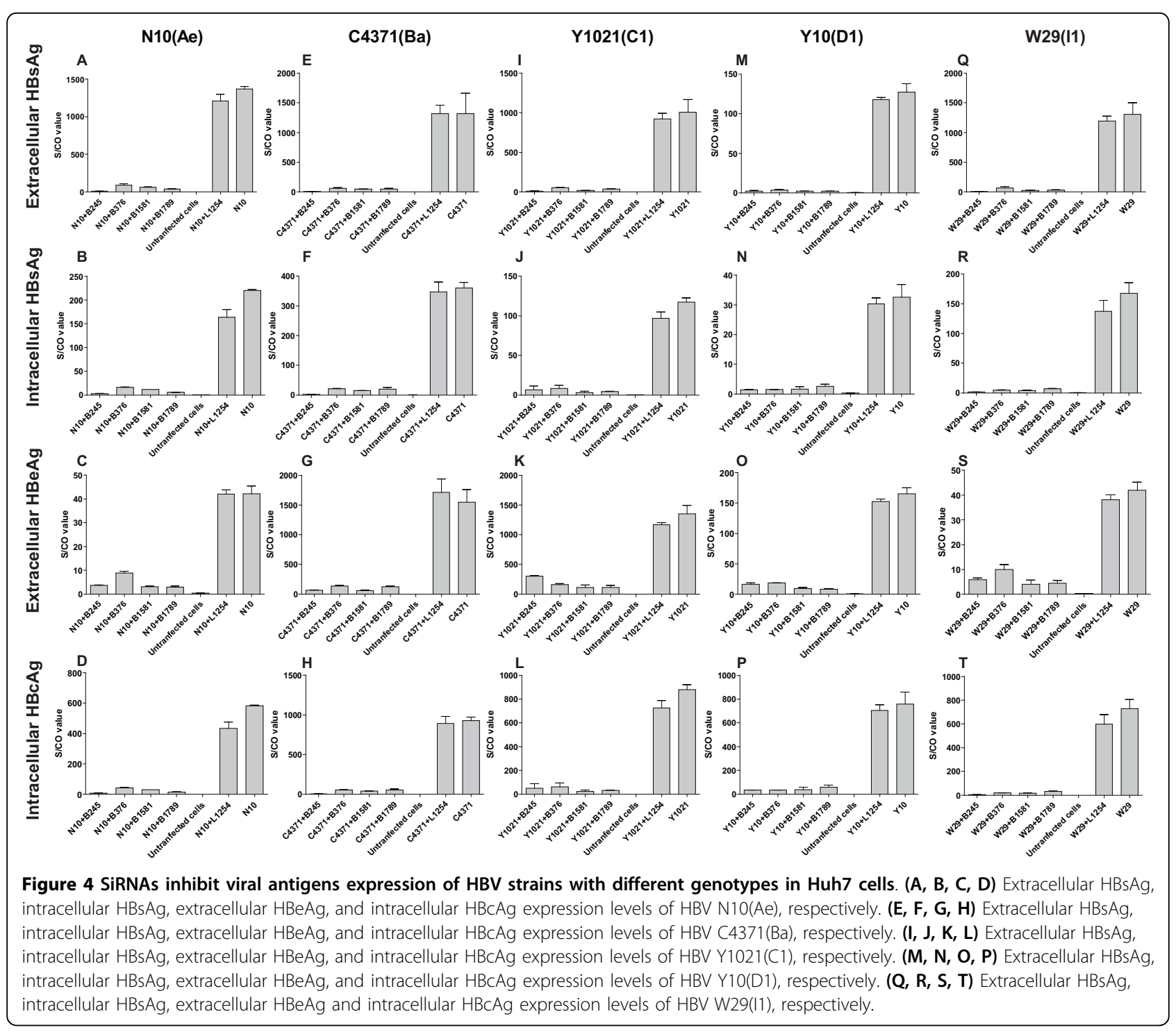

In shRNA expression systems, two different promoters are predominantly used: $\mathrm{U} 6$ and $\mathrm{H} 1$, both driven by human polymerase III (poly III). Compared to Pol II promoters, Pol III promoters generally possess a greater capacity to synthesize RNA transcripts of a higher yield and rarely induce interferon responses $[17,24]$. However, a previous study noted that U6 Pol III-expressed shRNAs may cause serious toxicity in vivo by saturating the endogenous miR pathway [25]. In this report, we constructed 40 shRNA plasmids (Table 1) with various targets, using a human H1 Pol III promoter. The target sequences of the final four selected shRNA plasmids demonstrated high sequence conservation among A to I genotypes and significant inhibition activity, in both Huh7 cells and mice, against the expressions of HBV RNA, DNA and antigens in genotypes A, B, C, D and I. The inhibitory efficacy of these shRNAs (B245, B376,
B1581 and B1789) however, varies significantly against the various genotypes for different viral markers in different models (Figure 3, 4, 5 and 6). Such differences in efficiency may be due to differences in the mRNA's secondary structure or the target site accessibility [26]. B245 was the most effective of the four candidates.

It should be noted that both the cell-transfection model and hydrodynamic injection model more closely resemble an acute model of a HBV infection. This is a potential limitation in this study, as most individuals who need anti-HBV therapy are chronically infected. Compared to the HBV transgenic mouse models and stably transfected cell lines, the former are more flexible and convenient in evaluating the efficacy of shRNAs as a way to inhibit various HBV strains. Nevertheless, the effective shRNA candidates should be studied further in different models. 


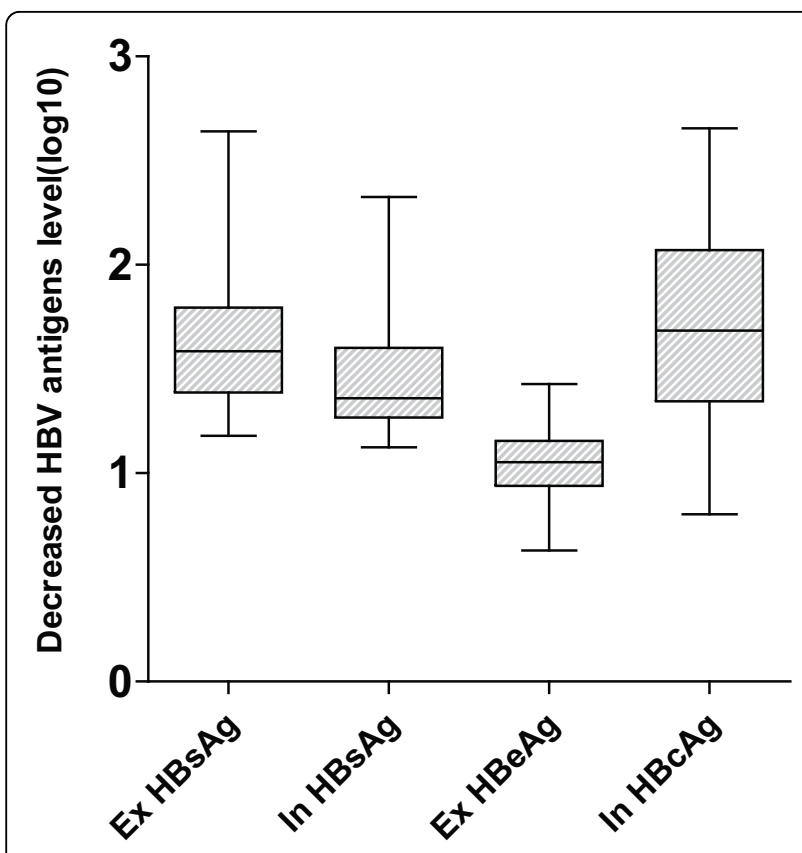

Figure 5 Comparing the RNAi-induced silencing effect on different viral markers. Data were displayed the average antigen level of the 4 siRNAs reduced for five HBV strains. "Ex" = Extracellular and "In" = Intracellular. The Mann-Whitney test was used to assess the difference. An asterisk represents a statistical difference of $\mathrm{P}<$ 0.01 in comparison with the other markers (Ex HBeAg vs. Others $P<$ 0.001, Ex HBsAg vs. In HBsAg $P=0.05$, Ex HBsAg vs. In HBcAg $P=$ 0.82 , In HBsAg vs. In $\mathrm{HBCAg} P=0.10$.)

Because HBV contains overlapping open reading frames (ORFs) and all four HBV transcripts overlap in their $3^{\prime}$ terminals, a single siRNA targeting multiple areas could be designed to maximize inhibitory potency [23]. The siRNAs targeting $C$ ORF, such as B2389 B2397, presented in Table 1, show activity only against the $3.5 \mathrm{~kb}$ pregenomic RNA, but are unlikely to show any activity against the other three transcripts (Figure 1). Meanwhile, all four siRNAs demonstrated more silencing activity with regards to HBsAg expression than HBeAg expression for various genotypes in the cell cultures and mice. The targets on both however were the same in the HBV transcripts for the two proteins (Figure 4 and Figure 5), which was also observed in a previous study [23]. HBcAg, a viral capsid correlated with viral replication $[27,28]$, was silenced as effectively as HBsAg, but HBeAg was not (Figure 4).

The registered agents currently available for the treatment of HBV infections, such as interferon and nucleoside analogues, can dramatically decrease HBV DNA levels and induce particular $\mathrm{HBeAg}$ loss, but will rarely cause HBsAg loss in chronic hepatitis B patients [29-32]. RNA interference, on the other hand, can theoretically be directed to cleave any target RNA, providing a novel methodology for anti-HBV therapy [33]. In the present study, and supported by other studies [13,34,35], using RNAi as an inhibitor for HBV effectively reduces viral antigen levels, including HBsAg. It can be speculated that RNAi-treatments may offer complementary effects for current anti-HBV therapy. However, the final application of RNAi-based anti-HBV drugs depends on the development of effective and safe RNAi delivery systems.

\section{Conclusions}

In summary, four candidate shRNA plasmids significantly inhibited HBV genotypes A, B, C, D and I in vitro and in vivo. A potential avenue of investigation would be a combination strategy of various siRNA in a single transcript to improve efficacy and also prevent or at least delay the rise of viral escape mutants.

\section{Methods \\ HBV Plasmids}

Five HBV 1.35-fold genome plasmids - N10 (genotype Ae, AY707087), C4371 (genotype Ba, GU357842), Y1021 (genotype C1, GU357845), Y10 (genotype D1, GU357846) and W29 (genotype I1, GU357844) were used for transfection and hydrodynamic injection. The constructions and molecular and phenotypic characteristics are described in our previous report [36].

\section{Bioinformatics Analysis}

To define the conservative sites on HBV genomes amongst the various genotypes, all available complete genome sequences of HBV, as of April 2009, were downloaded from GenBank. Multiple alignment was done with ClustalX2 under default settings (Gap Opening:10, Gap Extension: 0.2, Delay Divergent Sequences (\%): 30, DNA Transition Weight: 0.5, Use Negative Matrix: Off). The most representative and informative sequence in terms of phylogeny were collected as a dataset and the most similar sequences were removed using all pairwise distance scan. A total of $327 \mathrm{HBV}$ genomes including A-I genotypes and nearly all reported subtypes were remained in the final dataset. The genotypes and subtypes of six HBV genomes isolated in the study were submitted to phylogenetic analysis using MEGA 4.0 software (data not shown). Forty sites with conservative sequences were selected and the shRNA plasmids were constructed (Table 1). The designed siRNA were evaluated for potential off-target effects by the online SOS program http://rnai.cs.unm.edu/offTarget. The sequences and positions of the forty designed shRNA targets are shown in Table 1.

\section{ShRNA Plasmids}

ShRNA plasmids were cloned downstream of the human $\mathrm{H} 1$ promoter in the vector pSUPER [37]. The target 

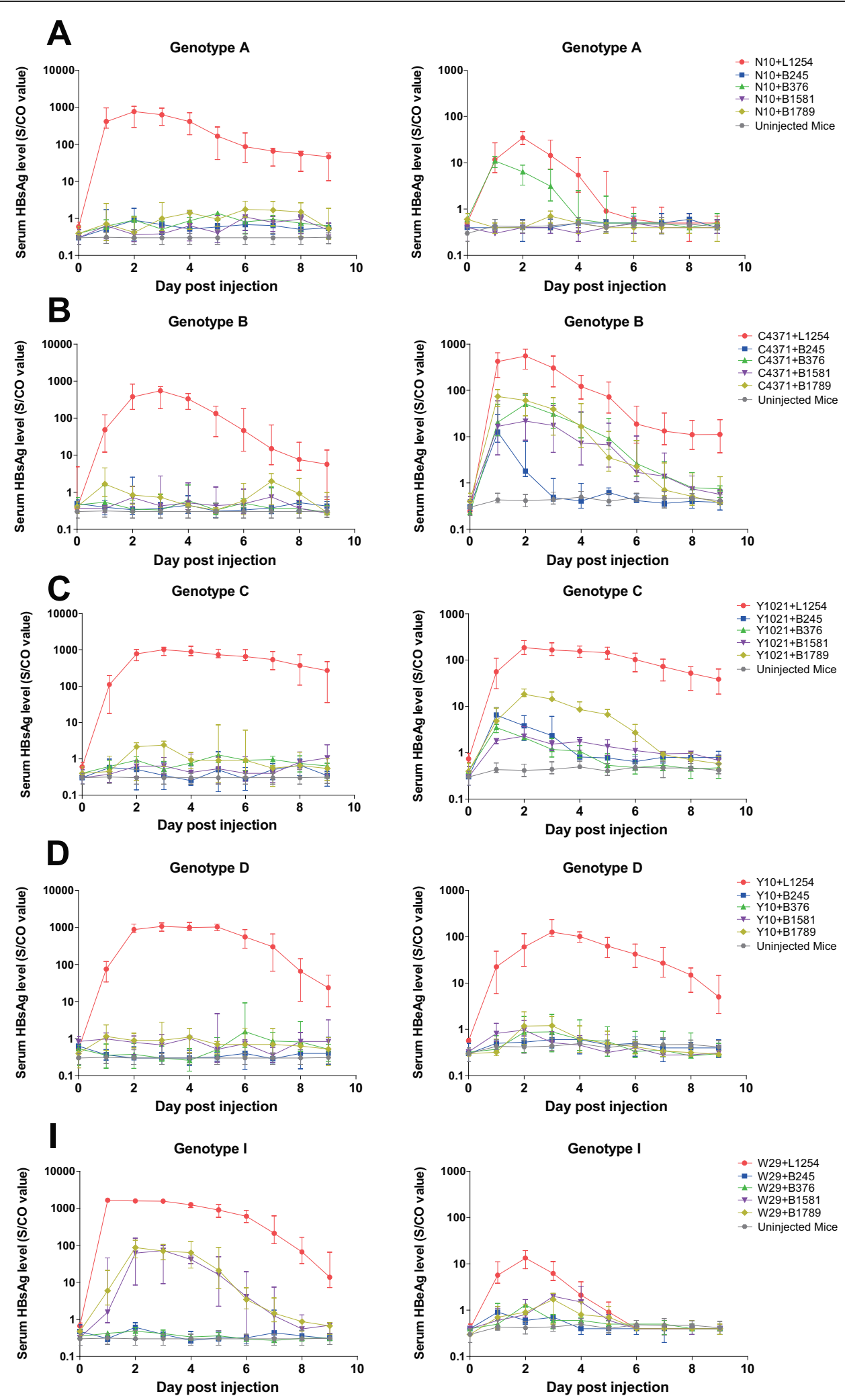

Figure 6 Kinetics of serum HBV antigen ( $\mathrm{HBsAg}$ and $\mathrm{HBeAg}$ ) of various HBV genotypes in RNAi-treated mice. For each group (each line in the figure), the experiment was repeated using two different groups of five mice. Due to limited serum resources, each sample was diluted 10-fold. (A) Genotype Ae (N10 group), (B) Genotype Ba (C4371 group), (C) Genotype C1 (Y1021 group), (D) Genotype D1 (Y10 group),

(E) Genotype I1 (W29 group). 
sites for siRNA were chosen based on conservative sites among the major HBV genotypes and subtypes. An shRNA plasmid targeting the firefly luciferase gene was used as a control (L1254: TGG CTA CAT TCT GGA GAC ATA).

\section{Cell Culture and In Vitro Transfection}

The plasmids used for in vitro transfection were purified with PlasmidSelect Xtra Starter Kit (GE Health, Sweden) and the concentrations were determined by the UVspectrophotometric method. To determine the ability of siRNA to inhibit HBV gene expression in cell cultures, Huh7 cells were co-transfected with $4 \mu \mathrm{g}$ of HBV plasmids, $1 \mu \mathrm{g}$ of shRNA plasmids and $0.4 \mu \mathrm{g}$ of a pcDNA3.1-SEAP plasmid using Lipofectamine 2000 (Invitrogen, Shanghai, China) following the manufacturer's instructions. They were then harvested four days later. The pcDNA3.1-SEAP plasmid is a reporter plasmid expressing secreted alkaline phosphatase and used for transfection efficiency standardization by estimating SEAP enzymatic activity (Pierce; Kunming, China) in the culture supernatant.

\section{Evaluation for Potential Adverse Effects of siRNA}

Possible adverse effects of shRNA on cells were evaluated using morphology criterion, growth rate assessment, and by noting the cytotoxicity profile of transfected cells. Cytotoxicity was determined through a WST-8 assay (Cell Counting Kit-8, Beyotime, Shanghai, China) $[38,39]$. The number of viable cells was then determined by absorbance measured at $450 \mathrm{~nm}$ on an automated plate reader. The potential off-target effects of siRNA were evaluated by monitoring the IFN response. Huh7 cells were transfected with $1 \mu \mathrm{g}$ of shRNA plasmids. Non-transfected cells treated or untreated with 500 IU of IFN $\alpha-2$ a (Anfulong, Huadali Company, China) for $24 \mathrm{~h}$ served as a positive control [40]. Expression profile of four major interferon-stimulated (STAT1, OAS1, GBP1 and MX1) were analyzed by a quantitative RT-realtime PCR using the previously reported primers while the GAPDH level served as a control[41].

\section{Mice Experiments}

To evaluate the anti-viral effects of siRNA in vivo, an HBV hydrodynamic injection was conducted in BALB/c mice. Briefly, $50 \mu \mathrm{g}$ of purified HBV plasmid and $10 \mu \mathrm{g}$ shRNA plasmids were diluted to $2 \mathrm{~mL}$ with physiological saline and then injected into the tail vein within 5$10 \mathrm{~s}$. Mice sera were assayed every day for $\mathrm{HBsAg}$ and $\mathrm{HBeAg}$ from Day 0 to Day 9. For each group, five mice aging from 4-6 weeks were used [42]. All animals received humane care and the study protocol complied with the institution's ethics guidelines.

\section{Measurement of HBV RNA and DNA}

For detection of the cytoplasmic HBV RNA, total RNA was extracted from cells using Tripure Isolation Reagent (Roche Applied Science, Switzerland) according to the manufacturer's instructions. Potential residual DNA contamination of RNA preparations were excluded by DNase I digestion. Ten nanograms of RNA were analysed by AccessQuick realtime RT-PCR System (Promega, USA) on a CFX96 instrument (Bio-Rad, USA). The HBV pg/pc (pregenomic/preCore) RNA level was detected by primers PGP (-CACCTCTGCCTAATCATC, nt1826-nt1843) and BC1 (GGAAAGAAGTCAGAAGGCAA, nt1974-nt1955) [43] using probe CP2 (HEX-ATGTTCATGTCCTACTGTTCAAGCC-BHQ2). The transcript copy number was normalized to those of GAPDH.

For the HBV DNA assay, $100 \mu \mathrm{L}$ of supernatant was pre-heated at $50^{\circ} \mathrm{C}$ for 20 minutes and then treated with $1 \mathrm{U}$ DNase I for 2 hours to eliminate residual plasmids. The reaction was terminated by EDTA at a final concentration of $10 \mathrm{mM}$. The mixture was then incubated at $70^{\circ} \mathrm{C}$ for $10 \mathrm{~min}$ and the HBV DNA was extracted using QIAamp DNA blood kits (QIAGEN, Hilden, Germany). HBV DNA quantification assays were performed using a commercial real-time PCR kit (Kehua, Shanghai, China).

\section{Determination of HBV Antigens}

$\mathrm{HBsAg}, \mathrm{HBeAg}$ and $\mathrm{HBcAg}$ levels were determined by chemiluminescence using commercial assay kits (Wantai, Beijing, China). The relative level of each antigen was expressed as an S/CO (signal/cutoff) value, on a linear range from 1 to 1000 for all three assays. The lower detection limit was $10 \mathrm{pg} / \mathrm{mL}$ for the $\mathrm{HBsAg}$ and $\mathrm{HBeAg}$ assays, and $50 \mathrm{pg} / \mathrm{ml}$ for the $\mathrm{HBcAg}$ assay. In regards to the intracelluar HBV antigen assay, the transfected cells were treated with a suitable lysis buffer (20 mM HEPES, $1 \mathrm{mM}$ EGTA, $100 \mathrm{mM} \mathrm{NaCl}, 5 \mathrm{mM} \mathrm{Mg} 2 \mathrm{Cl}, 0.4 \%$ $\mathrm{n}$-Dodecyl $\beta$-D- maltoside, $\mathrm{n}$-Dodecyl $\beta$-D-maltoside, and $10 \%$ Glycerol) at room temperature for 30 minutes and the supernatants were separated through centrifugation and used for immunoassay.

\section{Statistical Evaluation}

Statistical analyses were performed using independent Student $t$ test or Mann-Whitney U test (GraphPad Software, San Diego California USA,). Differences were considered to be statistically significant for $\mathrm{p}$ values $\leq 0.05$.

\section{Abbreviations}

SIRNA: small interfering RNA; SHRNA: short hairpin RNA; OFF-TARGET EFFECT: non-specific effects resulting from the introduction of siRNA: STAT1: signal transducers and activators of transcription 1; OAS1: 2'-5'oligoadenylate synthetase 1; $\mathbf{M X 1}$ : interferon-induced GTP-binding protein; 
GBP1: guanylate binding protein 1; HBV: hepatitis B virus; HBSAG: hepatitis B surface antigen; HBEAG: hepatitis B e antigen; HBCAG: hepatitis B core antigen.

\section{Acknowledgements}

This work was supported by a grant from Key Special Subjects of Infectious Diseases (2008ZX10002-011 and 2008ZX10002-012) and from the Excellent Youth Foundation of Fujian Scientific Committee (2009J06020). We gratefully acknowledge Lucy Zhu from McGill University for editorial assistance in writing this paper. We also thank Dr. Hai Yu and Dr. Chenghao Huang (NIDVD, Xiamen) for their technical help with this work.

\section{Authors' contributions}

YLZ, TC, JZ and NSX conceived the study, participated in its design and coordination and drafted the manuscript. YLZ and QY carried out the molecular genetic studies, analyzed the aligned sequences, found conserved targets, participated in the study design and were involved in the shRNA design. YZL and YJC constructed all shRNA plasmids. YZL, YJC, CL, TZ, DZX, RYL, LWY and YBW performed all cell and mice experiments (including all transfections, hydrodynamic injections, WST-8 assays, RT-PCR and chemiluminescence immunoassays). YLZ, YJC, TC and QY conducted the data analysis and interpretation. AEY, JWS, QY, JZ and NSX helped to draft the manuscript and critically revised its final version. TC, JZ and NSX obtained funding. All authors read and approved the final manuscript.

Received: 8 March 2010 Accepted: 10 August 2010 Published: 10 August 2010

\section{References}

1. Lee WM: Hepatitis B virus infection. N Engl J Med 1997, 337(24):1733-1745.

2. Beasley RP, Hwang LY, Lin CC, Chien CS: Hepatocellular carcinoma and hepatitis B virus. A prospective study of 22707 men in Taiwan. Lancet 1981, 2(8256):1129-1133.

3. Mast EE, Alter MJ, Margolis HS: Strategies to prevent and control hepatitis B and C virus infections: a global perspective. Vaccine 1999, 17(1314):1730-1733.

4. Vial T, Descotes J: Clinical toxicity of the interferons. Drug Saf 1994, 10(2):115-150.

5. Fattovich G, Giustina G, Favarato S, Ruol A: A survey of adverse events in 11,241 patients with chronic viral hepatitis treated with alfa interferon. $J$ Hepatol 1996, 24(1):38-47.

6. Liaw YF: Antiviral therapy of chronic hepatitis B: opportunities and challenges in Asia. J Hepatol 2009, 51(2):403-410.

7. Fire A, Xu S, Montgomery MK, Kostas SA, Driver SE, Mello CC: Potent and specific genetic interference by double-stranded RNA in Caenorhabditis elegans. Nature 1998, 391(6669):806-811.

8. Elbashir SM, Harborth J, Lendeckel W, Yalcin A, Weber K, Tuschl T: Duplexes of 21-nucleotide RNAs mediate RNA interference in cultured mammalian cells. Nature 2001, 411(6836):494-498.

9. Paddison PJ, Caudy AA, Bernstein E, Hannon GJ, Conklin DS: Short hairpin RNAs (shRNAs) induce sequence-specific silencing in mammalian cells. Genes Dev 2002, 16(8):948-958.

10. McCaffrey AP: RNA interference inhibitors of hepatitis B virus. Ann N Y Acad Sci 2009, 1175:15-23.

11. Deng L, Li G, Xi L, Yin A, Gao Y, You W, Wang X, Sun B: Hepatitis B Virus Inhibition in Mice by Lentiviral Vector Mediated Small Interference RNA. BMC Gastroenterol 2009, 9(1):73.

12. Yang PL, Althage A, Chung J, Chisari FV: Hydrodynamic injection of viral DNA: a mouse model of acute hepatitis B virus infection. Proc Natl Acad Sci USA 2002, 99(21):13825-13830.

13. McCaffrey AP, Nakai H, Pandey K, Huang Z, Salazar FH, Xu H, Wieland SF, Marion PL, Kay MA: Inhibition of hepatitis B virus in mice by RNA interference. Nat Biotechnol 2003, 21(6):639-644.

14. Shlomai A, Shaul Y: Inhibition of hepatitis B virus expression and replication by RNA interference. Hepatology 2003, 37(4):764-770.

15. Ying RS, Zhu C, Fan XG, Li N, Tian XF, Liu HB, Zhang BX: Hepatitis B virus is inhibited by RNA interference in cell culture and in mice. Antiviral Res 2007, 73(1):24-30.

16. Giladi H, Ketzinel-Gilad M, Rivkin L, Felig Y, Nussbaum O, Galun E: Small interfering RNA inhibits hepatitis B virus replication in mice. Mol Ther 2003, 8(5):769-776
17. Chen $Y$, Cheng G, Mahato Rl: RNAi for treating hepatitis $B$ viral infection. Pharm Res 2008, 25(1):72-86.

18. Ely A, Naidoo T, Mufamadi S, Crowther C, Arbuthnot P: Expressed anti-HBV primary microRNA shuttles inhibit viral replication efficiently in vitro and in vivo. Mol Ther 2008, 16(6):1105-1112.

19. Olinger CM, Jutavijittum $P$, Hubschen JM, Yousukh A, Samountry B, Thammavong T, Toriyama K, Muller CP: Possible new hepatitis B virus genotype, southeast Asia. Emerg Infect Dis 2008, 14(11):1777-1780.

20. Tran TT, Trinh TN, Abe K: New complex recombinant genotype of hepatitis B virus identified in Vietnam. J Virol 2008, 82(11):5657-5663.

21. Colson $P$, Roquelaure $B$, Tamalet $C$ : Detection of a newly identified hepatitis B virus genotype in southeastern France. J Clin Virol 2009, 45(2):165-167.

22. Sugiyama M, Tanaka Y, Kato T, Orito E, Ito K, Acharya SK, Gish RG, Kramvis A, Shimada T, Izumi N, et al: Influence of hepatitis B virus genotypes on the intra- and extracellular expression of viral DNA and antigens. Hepatology 2006, 44(4):915-924.

23. Wu HL, Huang LR, Huang CC, Lai HL, Liu CJ, Huang YT, Hsu YW, Lu CY, Chen DS, Chen PJ: RNA interference-mediated control of hepatitis $B$ virus and emergence of resistant mutant. Gastroenterology 2005, 128(3):708-716.

24. Medina MF, Joshi S: RNA-polymerase III-driven expression cassettes in human gene therapy. Curr Opin Mol Ther 1999, 1(5):580-594.

25. Grimm D, Streetz KL, Jopling CL, Storm TA, Pandey K, Davis CR, Marion P, Salazar F, Kay MA: Fatality in mice due to oversaturation of cellular microRNA/short hairpin RNA pathways. Nature 2006, 441(7092):537-541.

26. Keck K, Volper EM, Spengler RM, Long DD, Chan CY, Ding Y, McCaffrey AP: Rational design leads to more potent RNA interference against hepatitis B virus: factors effecting silencing efficiency. Mol Ther 2009, 17(3):538-547.

27. Bredehorst $R$, von Wulffen $H$, Granato C: Quantitation of hepatitis B virus (HBV) core antigen in serum in the presence of antibodies to HBV core antigen: comparison with assays of serum HBV DNA, DNA polymerase, and HBV e antigen. J Clin Microbiol 1985, 21(4):593-598.

28. Kimura T, Rokuhara A, Matsumoto A, Yagi S, Tanaka E, Kiyosawa K, Maki N: New enzyme immunoassay for detection of hepatitis $B$ virus core antigen $(\mathrm{HBCAg})$ and relation between levels of $\mathrm{HBCAg}$ and $\mathrm{HBV}$ DNA. Clin Microbiol 2003, 41(5):1901-1906.

29. Janssen $\mathrm{HL}$, van Zonneveld M, Senturk $H$, Zeuzem S, Akarca US, Cakaloglu Y, Simon C, So TM, Gerken G, de Man RA, et al: Pegylated interferon alfa-2b alone or in combination with lamivudine for HBeAgpositive chronic hepatitis B: a randomised trial. Lancet 2005, 365(9454):123-129.

30. EASL: [EASL clinical practice guidelines. Management of chronic hepatitis B]. Gastroenterol Clin Biol 2009, 33(6-7):539-554.

31. Papatheodoridis GV, Manolakopoulos S: EASL clinical practice guidelines on the management of chronic hepatitis B: the need for liver biopsy. J Hepatol 2009, 51(1):226-227.

32. Stroffolini T, Gaeta GB, Mele A: AASLD Practice Guidelines on chronic hepatitis B and HBV infection in Italy. Hepatology 2007, 46(2):608-609, author reply 609.

33. Arbuthnot $P$, Longshaw $V$, Naidoo T, Weinberg MS: Opportunities for treating chronic hepatitis $B$ and $C$ virus infection using RNA interference. J Viral Hepat 2007, 14(7):447-459.

34. Moore MD, McGarvey MJ, Russell RA, Cullen BR, McClure MO: Stable inhibition of hepatitis $B$ virus proteins by small interfering RNA expressed from viral vectors. J Gene Med 2005, 7(7):918-925.

35. Hamasaki K, Nakao K, Matsumoto K, Ichikawa T, Ishikawa H, Eguchi K: Short interfering RNA-directed inhibition of hepatitis $B$ virus replication. FEBS Lett 2003, 543(1-3):51-54.

36. Yu H, Yuan Q, Ge SX, Wang HY, Zhang YL, Chen QR, Zhang J, Chen PJ, Xia NS: Molecular and phylogenetic analyses suggest an additional hepatitis B virus genotype "i". PLoS One 2010, 5(2):e9297.

37. Brummelkamp TR, Bernards R, Agami R: A system for stable expression of short interfering RNAs in mammalian cells. Science 2002, 296(5567):550-553.

38. Shiokawa T, Hattori Y, Kawano K, Ohguchi Y, Kawakami H, Toma K, Maitani Y: Effect of polyethylene glycol linker chain length of folatelinked microemulsions loading aclacinomycin A on targeting ability and antitumor effect in vitro and in vivo. Clin Cancer Res 2005, 11(5):2018-2025. 
39. Ishiyama M, Tominaga H, Shiga M, Sasamoto K, Ohkura Y, Ueno K: A combined assay of cell viability and in vitro cytotoxicity with a highly water-soluble tetrazolium salt, neutral red and crystal violet. Biol Pharm Bull 1996, 19(11):1518-1520

40. Sun D, Rosler C, Kidd-Ljunggren K, Nassal M: Quantitative assessment of the antiviral potencies of 21 shRNA vectors targeting conserved, including structured, hepatitis B virus sites. J Hepatol 2010, 52(6):817-826.

41. Liang YG, Liu HY, Liu BX, Bai Y, Wu H, Zhou QH, Chen J: Detection of IFN Response of Non-Specific Effects on RNAi. Chin J Lung Cancer 2009, 12(1):16-22.

42. Wang SH, Yeh SH, Lin WH, Wang HY, Chen DS, Chen PJ: Identification of androgen response elements in the enhancer I of hepatitis $B$ virus: $A$ mechanism for sex disparity in chronic hepatitis B. Hepatology 2009.

43. Jammeh S, Thomas HC, Karayiannis P: Replicative competence of the T1311, K141E, and G145R surface variants of hepatitis B Virus. J Infect Dis 2007, 196(7):1010-1013.

doi:10.1186/1471-2180-10-214

Cite this article as: Zhang et al:: RNA Interference inhibits Hepatitis B Virus of different genotypes in Vitro and in Vivo. BMC Microbiology 2010 10:214.

\section{Submit your next manuscript to BioMed Central} and take full advantage of:

- Convenient online submission

- Thorough peer review

- No space constraints or color figure charges

- Immediate publication on acceptance

- Inclusion in PubMed, CAS, Scopus and Google Scholar

- Research which is freely available for redistribution

Submit your manuscript at www.biomedcentral.com/submit 